\title{
Asymmetric synthesis: From transition metals to organocatalysis*
}

\author{
Pavel Kočovský $\ddagger$ and Andrei V. Malkov ${ }^{\dagger}$ \\ Department of Chemistry, WestChem, University of Glasgow, Glasgow G12 8QQ, \\ Scotland, UK
}

\begin{abstract}
Umpolung in the allylation reaction is discussed with examples drawn from transition-metal-catalyzed allylic substitution (with the allylic unit acting as an electrophile) and Lewis base-catalyzed allylation of aldehydes with allyltrichlorosilane (with the allyl acting as a nucleophile). Iridium-catalyzed electrophilic allylation of $O$-nucleophiles has been employed in our new approach to $C$-nucleoside analogs, where the $\mathrm{C}-\mathrm{O}$ bond (rather than $\mathrm{C}-\mathrm{C}$ ) was constructed stereospecifically. Variation of the absolute configuration in the starting segments allowed the synthesis of all four combinations of $D / L-\alpha / \beta$-ribosides. In the nucleophilic allylation of aldehydes, chiral pyridine-type $\mathrm{N}$-oxide catalysts are presented, in particular QUINOX and METHOX, and the intriguing behavior of QUINOX is discussed. Here, the $\pi-\pi$ interactions between the substrate aldehyde and the catalyst are suggested to rationalize the experimental observations. Good correlation between the calculated energies for the transition states and the experimentally observed enantioselectivities has been obtained.
\end{abstract}

Keywords: umpolung; allylation; transition-metal-catalyzed; allyltrichlorosilane; Ir-catalyzed; ribosides; QUINOX; METHOX.

\section{INTRODUCTION}

Allylation is a synthetic transformation of particular importance since the allylic group thus introduced can be regarded as a relatively benign surrogate of a polyfunctional segment, into which it can be subsequently elaborated without the need for extensive protection/deprotection. Two approaches, characterized by opposite polarity, can be considered as a typical example of umpolung (Scheme 1): one employing the allylic moiety as an electrophile $(\mathbf{1} \rightarrow \mathbf{2})$ and one as a nucleophile $(\mathbf{3} \rightarrow \mathbf{4})$.
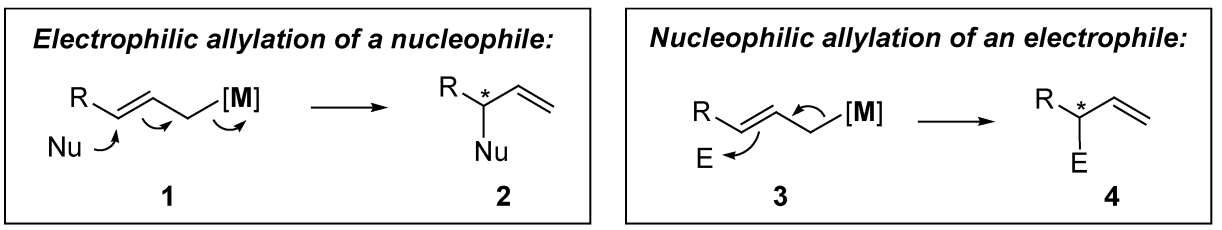

Scheme 1 Umpolung in the allylation reaction.

\footnotetext{
*Paper based on a presentation at the $14^{\text {th }}$ International Symposium on Organometallic Chemistry Directed Towards Organic Synthesis (OMCOS-14), 2-6 August 2007, Nara, Japan. Other presentations are published in this issue, pp. 807-1194.

‡Corresponding author: E-mail: pavelk@chem.gla.ac.uk

†E-mail: amalkov@chem.gla.ac.uk.
} 


\section{ELECTROPHILIC ALLYLATION CATALYZED BY TRANSITION METALS}

The metal-catalyzed electrophilic allylation represents a stereo- and regiocontrolled variant of the classical but rather capricious $\mathrm{S}_{\mathrm{N}} 2 / \mathrm{S}_{\mathrm{N}} 2$ substitution [1]. Thus, the $\mathrm{Pd}(0)$-catalyzed version [2] is known to occur via the intermediate $\eta^{3}$-complex $6(\mathrm{M}=\mathrm{Pd})$, arising from the allylic substrate $5(\mathrm{X}=\mathrm{OAc}$, $\mathrm{OCO}_{2} \mathrm{Me}$, etc.) via inversion of configuration (Scheme 2) [2]. The subsequent reaction of $\mathbf{6}$ with the malonate anion and other stabilized $C$-nucleophiles again proceeds with inversion $(6 \rightarrow 7)$ [2], giving an overall retention. By contrast, organometallics and nonstabilized nucleophiles react with retention in the second step $(\mathbf{6} \rightarrow \mathbf{9})$ owing to the initial coordination of the nucleophile to the metal M, followed by an internal migration [2].
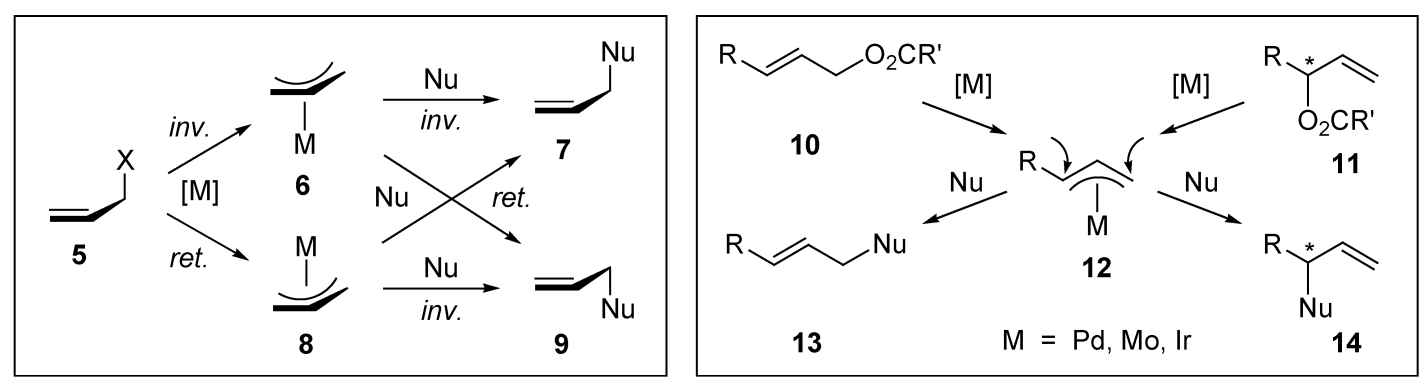

Scheme 2 Stereo- and regiochemistry of the metal-catalyzed electrophilic allylation of a nucleophile.

Although the $\operatorname{Pd}(0)$-catalyzed reaction is dominated by inversion in the first step $(\mathbf{5} \rightarrow \mathbf{6})$, the retention pathway $(\mathbf{5} \rightarrow \mathbf{8})$ can be enforced, in some instances, by precoordination of the catalyst either to the leaving group or to another group present in the allylic substrate, as first demonstrated by us [3] and by Kurosawa [4], and later confirmed by other groups [5]. Using the same philosophy, the $\mathrm{Ni}(0)$-catalyzed reaction of an allylic substrate with a Grignard reagent has been shown by us to be altered by a coordinating neighboring group to an overall retention via the ret-ret mechanism $(\mathbf{5} \rightarrow \mathbf{8} \rightarrow \mathbf{7})$ [3c].

Group 6 complexes have also been shown to catalyze allylic substitution and to give products of an overall retention of configuration $(5 \rightarrow 7)$ [6,7]. We have provided the first evidence that the reaction with malonate nucleophiles, catalyzed by $\mathrm{Mo}(\mathrm{CO})_{6}$, can occur via a double retention $(\mathbf{5} \rightarrow \mathbf{8} \rightarrow \mathbf{7})$ $[8,9]$, in stark contrast to the $\operatorname{Pd}(0)$-catalyzed reaction; this mechanism was later corroborated by LloydJones and Krska [10]. Rhodium and iridium complexes, also known to catalyze allylic substitution, exhibit retention of configuration, which is believed to originate from double inversion [11-14].

Regiochemistry of the transition-metal-catalyzed allylic substitution represents another intriguing issue. Thus, Pd is known to prefer the attack at the less substituted terminus of the nonsymmetrical $\eta^{3}$-complex 12, affording the linear product 13, generally irrespective of whether the terminal or branched allylic substrate 10/11 was used [2,15]. By contrast, Mo, W, Rh, and Ir complexes favor the formation of the branched product $\mathbf{1 4}[6,7,11-14]$. However, the whole picture is further complicated by the "memory effect" that had been extensively studied with Pd [16,17]. Here, if the $\eta^{3}$-complex 12 is generated, its behavior should be, a priori, independent of the starting material, i.e., of whether the linear (10) or branched (11) allylic substrate was used as the starting material. Nevertheless, this may not always be the case: examples of the preferential conversion of the branched allylic substrate $\mathbf{1 1}$ into the branched product $\mathbf{1 4}$ have been observed by us and by others [15-17], and the specific conditions, under which the memory effect operates, have been outlined [17].

Enantiocontrol in the transition-metal-catalyzed allylic substitution has been attained by using various chiral ligands. Thus, in the case of symmetrical $\eta^{3}$-complexes, a suitable chiral ligand can control the preferential nucleophilic attack at one of the termini of the allylic system, which in turn results 
in the formation of one enantiomer in preference [18]. In the case of $\mathrm{Mo}(0)$, where the linear substrate 10 is known to afford mainly the branched (chiral) product 14, application of chiral ligands has led to high enantioselectivity $[19,20]$. However, the racemic branched allylic substrate $\mathbf{1 1}$ has also been found to produce mainly one enantiomer of 14, implying that an isomerization of one enantiomer of $\mathbf{1 1}$ must occur during the reaction. Using isotopic labeling, we have been able to show that this isomerization occurs via the corresponding $\eta^{1}$-allylic complex 1 [20b].

\section{IRIDIUM-CATALYZED ALLYLATION IN THE SYNTHESIS OF $\boldsymbol{C}$-NUCLEOSIDES}

While natural and synthetic $N$-nucleosides (Scheme 3), such as uridine (15), are vulnerable to enzymatic attack and acid-catalyzed hydrolysis, their $C$-analogs, such as pseudouridine (16) and showdomycin (17), are much more stable (compare the acid-sensitive aminal moiety in $\mathbf{1 5}$ with the robust ether link in $\mathbf{1 6}$ and 17). Furthermore, unnatural analogs, such as the homologated deoxyuridine $\mathbf{1 8}$ or the difluoroderivate 19, capable of $\pi$-stacking, have been intensively studied both as interesting building blocks in chemical biology and as targets in medicinal chemistry [21]. However, in spite of the increased interest in $C$-nucleosides, the methodology for their synthesis is rather limited and requires further development [22]. We believed that transition-metal-catalyzed allylic substitution could be utilized in a novel approach to these important targets and could eliminate some of the existing deficiencies in the synthetic methodology in this area.<smiles></smiles>

Scheme 3 Examples of natural and synthetic nucleosides.

Most of the currently available methods for the synthesis of $C$-nucleosides rely on the construction of the $\mathrm{C}-\mathrm{C}$ bond between the carbohydrate moiety and the aromatic/heteroaromatic group (A; Scheme 4), e.g., by using modified glycosylating reagents or the Heck addition of a suitable arene derivative to a glycal [22]. Since these methods are often characterized by low stereoselectivity or instability of the intermediates, we have embarked on a new strategy that would require a stereoselective construction of the $\mathrm{C}-\mathrm{O}$ bond $(\mathbf{B}$ or $\mathbf{C})$ from a suitable $O$-nucleophile and an allylic electrophile. Four approaches to the key intermediate 22, whose cyclization via ring-closing metathesis should give dihydrofuran 26, can be envisaged: thus, alkoxide 20, generated from the monoprotected enantiopure 3-butene-1,2-diol, can be expected to react with the allylic substrate $\mathbf{2 1}$ or its isomer $\mathbf{2 3}$ (pathways $\boldsymbol{a}$ and b). Alternatively, the enantiopure allylic alkoxide $\mathbf{2 5}$ would serve as a nucleophile in the reaction with the allylic substrate $\mathbf{2 4}$ or $\mathbf{2 7}$ (pathways $\boldsymbol{c}$ and $\boldsymbol{d}$ ). Note that pathways $\boldsymbol{a}$ and $\boldsymbol{c}$ would require the use of one enantiopure reactant and a chiral catalyst, whereas pathways $\boldsymbol{b}$ and $\boldsymbol{d}$ would make use of two enantiopure reactants each and a nonchiral metal catalyst.

The enantiopure 3-butene-1,2-diol, as a precursor to the monoprotected alkoxide 20, is commercially available in both enantiomeric forms from butadiene, whereas the nonchiral, protected allylic substrate $\mathbf{2 4}$ can be obtained from the commercially available 2-butene-1,4-diol. The nonchiral cinnamyltype substrate $\mathbf{2 1}$ is a textbook synthetic target that can be prepared from the corresponding aldehyde via the Wittig-type methodology. 

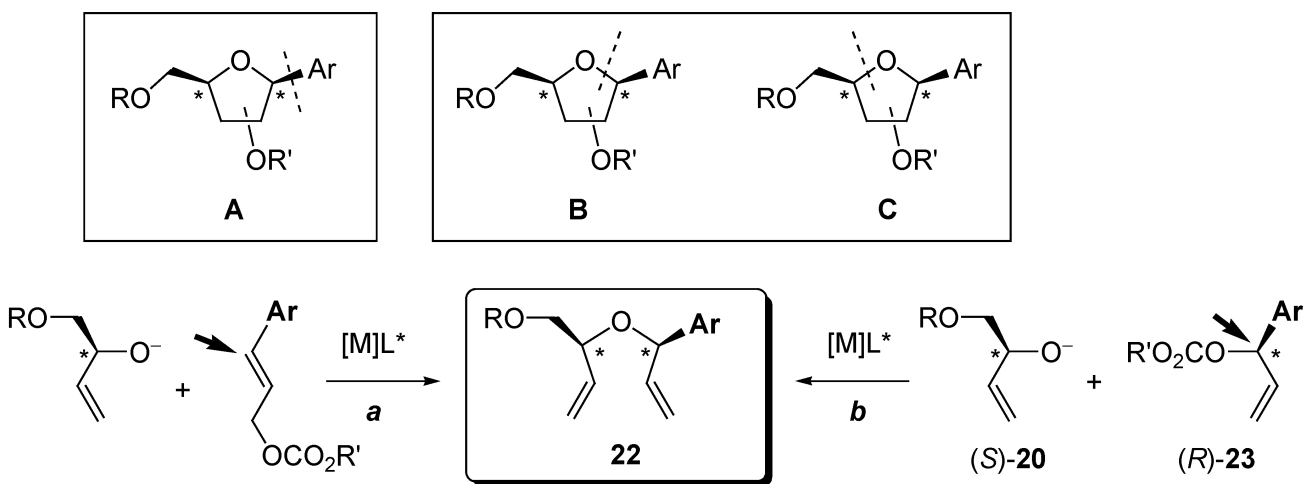

(S)-20

21<smiles>[R6]CC(C)=CCO[R20]</smiles>

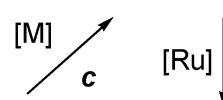<smiles>[R]Cc1ccc([Al])o1</smiles>

26
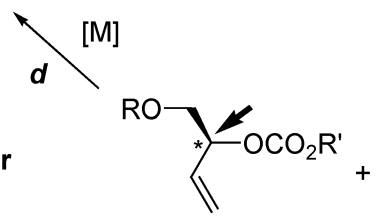

(S)-27<smiles>C=C[C+]([O-])[18O]</smiles>

$(R)-25$

Scheme 4 Retrosynthetic analysis.

The synthesis of the enantiopure iso-cinnamyl substrates $\mathbf{2 3}$ and $\mathbf{2 5}$ requires a reliable methodology for the production of the corresponding alcohols. Addition of $\mathrm{CH}_{2}=\mathrm{CHSi}(\mathrm{OMe})_{3}$ to the corresponding aldehyde 28 (Scheme 5), catalyzed by CuF [23], seemed promising but required an expensive chiral ligand (Segphos) and turned out, in our hands, insufficiently enantioselective in some cases. On the other hand, resolution of racemic iso-cinnamyl alcohols ( \pm )-29 via acetylation with isopropenyl acetate, catalyzed by the solid-supported Novozyme 435 , proved very practical in all instances, affording the $(R)$-acetates $(R)$-30 and unreacted $(S)$-alcohols $(S)$-29 in $\geq 99 \%$ ee each, which were readily separated by chromatography. The conversion of the enantiomeric alcohols into the corresponding $t$-butyl carbonates 31 required deprotonation with $n$-BuLi, followed by quenching with BOC-anhydride [24], which minimized the tendency to allylic rearrangement.

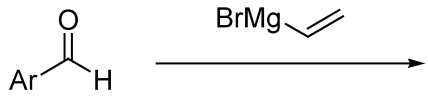

28<smiles>C=CC(O)Br</smiles>

$( \pm)-29$<smiles>C=C[C+](O)[17O]</smiles>

(S)-29

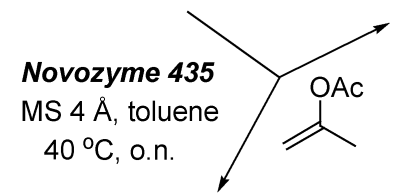

2. $(\mathrm{BOC})_{2} \mathrm{O}, \mathrm{rt} 3 \mathrm{~h}$
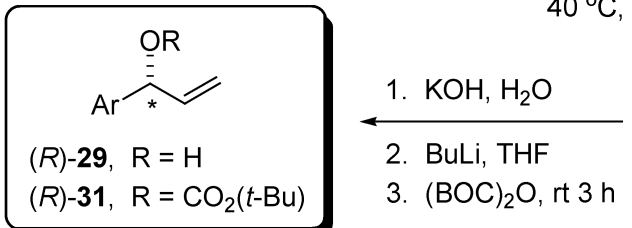

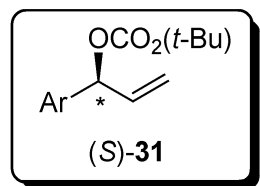

Scheme 5 Synthesis of the enantiopure iso-cinnamyl carbonates; for Ar, see Scheme 8. 
Transition-metal-catalyzed nucleophilic substitution of the cinnamyl-type carbonates 21 with $\mathrm{MeOH}, \mathrm{PhCH}_{2} \mathrm{OH}$, and other simple alcohols has been shown by Evans [12], Hartwig [13], and others [14] to require the use of the corresponding $\mathrm{Cu}(\mathrm{I})$ alkoxide as the $O$-nucleophile, which in turn can be generated from the alcohol by deprotonation with $n$-BuLi, followed by transmetallation with $\mathrm{CuI}$. In the reactions catalyzed by iridium, various chiral ligands, in particular Feringa-Alexakis phosphorus amidites [25], have been reported to induce high enantioselectivity [13,14b]. When applied to our cinnamyl carbonates 21, in combination with the chiral $\mathrm{Cu}(\mathrm{I})$ alkoxide 32 (following pathway $\boldsymbol{a}$ in Scheme 5), the Ir-catalyzed reaction proved highly regioselective in favor of the desired branched ether 33 (Scheme 6). However, diastereoselectivity of this reaction was unacceptably low, reaching the maximum of $\sim 40 \%$ de with ligand $\mathbf{3 4}$; other related ligands gave inferior results.

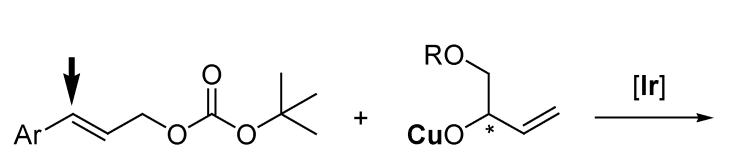

21
32<smiles>[R6]CC(=C)OC([Al])C=C</smiles>

33

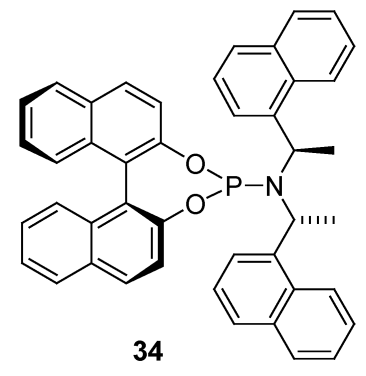

34

Scheme 6 Iridium-catalyzed allylic sybstitution ( $\mathrm{R}$ = Piv, Trt, TBDPS, TBDMS); for Ar, see Scheme 8.

Since the cinnamyl carbonates exhibited mediocre stereoselectivity, we turned to their enantiopure iso-cinnamyl isomers $\mathbf{2 3}$ (pathway $\boldsymbol{b}$ in Scheme 5). Optimization of the catalyst led to the simple phosphine-free, commercially available $[(\mathrm{COD}) \mathrm{IrCl}]_{2}$. This complex exhibited excellent regio- and diastereoselectivity, affording practically pure iso-cinnamyl ethers $\mathbf{3 8}$ from carbonates $(R)-\mathbf{3 1}$ and the $\mathrm{Cu}(\mathrm{I})$ alkoxide, generated from the enantiopure mono-protected diol (S)-36 (Scheme 7) [26]. Ruthenium-catalyzed ring-closing metathesis of $\mathbf{3 8}$ afforded the enantiopure cis-derivatives $\mathbf{3 9}$ [27], whose dihydroxylation, catalyzed by ruthenium with $\mathrm{NaIO}_{4}$ as the stoichiometric oxidant [28], gave rise to diols $\mathbf{4 0}$. Deprotection of the latter derivatives afforded D-ribosides $\mathbf{4 1}$.<smiles>C=CC(=[Zn])OC(=O)OCC(C)(C)C</smiles>

$(R)-31$<smiles>C=CC(O)COCC</smiles>

1. $n$-BuLi 2. Cul

(S)-36<smiles>C=CC(CC)O[Ge]</smiles>

$(S)-37$
35

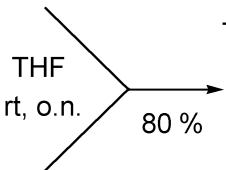<smiles>C=CC(COCC(C)C)OC(=C)COCC</smiles>

$\left(\mathrm{Cy}_{3} \mathrm{P}\right)_{2} \mathrm{Cl}_{2} \mathrm{Ru}={ }^{\mathrm{Ph}} \mid 95 \%$

$\mathrm{RuCl}_{3}$<smiles>CCNC(=O)[Al]c1oc(CO)c(O)c1O</smiles><smiles>CCCCCOCc1oc(Br)c(O)c1O</smiles>

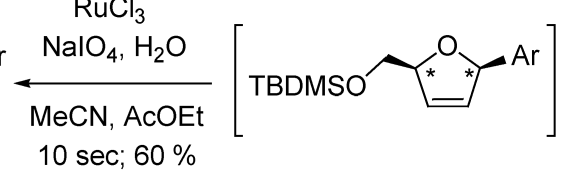

Scheme 7 Synthesis of $C$-ribosides; for Ar, see Scheme 8. 
By further combination we were able to generate a small library of D- and L- $\beta$-ribosides (Scheme 8 ), generally in good overall yields and with excellent stereoselectivity, which demonstrates the versatility of this approach. In analogy, $(R)$-31 afforded the corresponding D- and L- $\alpha$-ribosides.

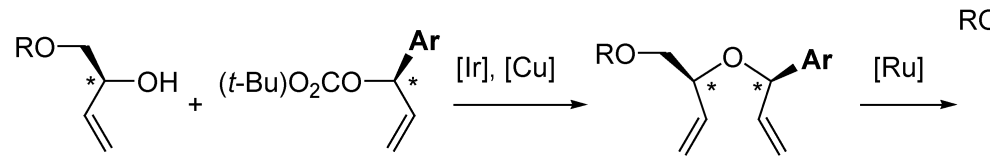

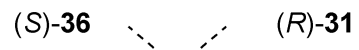<smiles>CC(C)(C)C</smiles>

$(R)-31$<smiles>C=CC(=O)OC(C)(C)C</smiles>

(S)-31<smiles>C=CC(O)CO[Mg]</smiles>

$(R)-36$<smiles>C=CC(COCC(C)C)OC(C)C</smiles>
$\stackrel{[\mathrm{Ru}]}{\longrightarrow}$<smiles>CC(C)(C)c1ccc(Br)cc1</smiles><smiles>CCCCCCCCCCc1ccc(OC)c(OC)c1</smiles><smiles>CC1(CO)O[C@@](C)(Br)C(O)C1O</smiles>

$\beta$-D-riboside<smiles>CC1(CO)OC(O)C(O)C1(C)O</smiles>

$\beta$-L-riboside

Ar:<smiles>CC(C)(C)c1ccccc1</smiles>

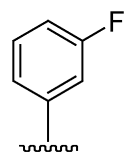

Scheme 8 Synthesis of D- and L-ribosides $(\mathrm{R}=\mathrm{TBDMS})$.

\section{ORGANOCATALYZED ALLYLATION OF ALDEHYDES WITH ALLYL TRICHLOROSILANES}

Allylation of aldehydes, such as 41, with the corresponding Grignard reagent (Scheme 9) is a textbook example that would be rather difficult to run in an enantioselective, catalytic fashion [29]. On the other hand, allylation can also be attained with AllylSiMe 3 and its congeners in the presence of a Lewis acid, which coordinates to the carbonyl group [30]. Since the coordinated species is much more reactive than the free aldehyde, only a catalytic amount of the Lewis acid is required. Naturally, if the Lewis acid is chiral, an enantioselective reaction can be expected [30]. Alternatively, addition of a Lewis base should enhance the reactivity of the nucleophilic silane, which in turn should also lead to allylation. However,

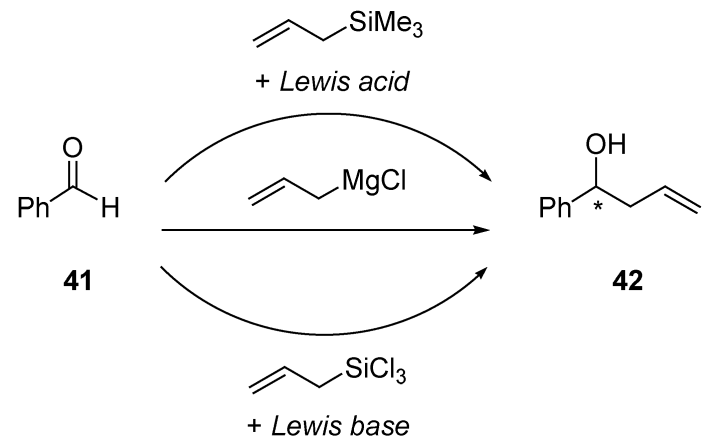

Scheme 9 Nucleophilic allylation of aldehydes. 
Lewis bases, such as DMF [31,32], DMSO [31,33], and HMPA [33,34] are typically inert to AllylSiMe 3 and require $\mathrm{AllylSiCl}_{3}$ [35], whose silicon atom is more Lewis acidic [30-36].

If the latter reaction proceeds through a closed transition state (45 in Scheme 10), good diastereocontrol can be expected in the case of trans- and cis-CrotylSiCl 3 (43) [37,38]: Here, the anti-diastereoisomer of $\mathbf{4 8}$ should be obtained from trans-crotyl derivative, whereas the syn-isomer of $\mathbf{4 8}$ should result from the reaction of the cis-isomer of 43. Furthermore, the chiral information can be expected to be conveyed from the Lewis base to the product, so that one enantiomer should be obtained in preference. Provided the Lewis base dissociates from the intermediate $\mathbf{4 6}$ with sufficient rate, it can act as a catalyst (rather than a stoichiometric reagent).

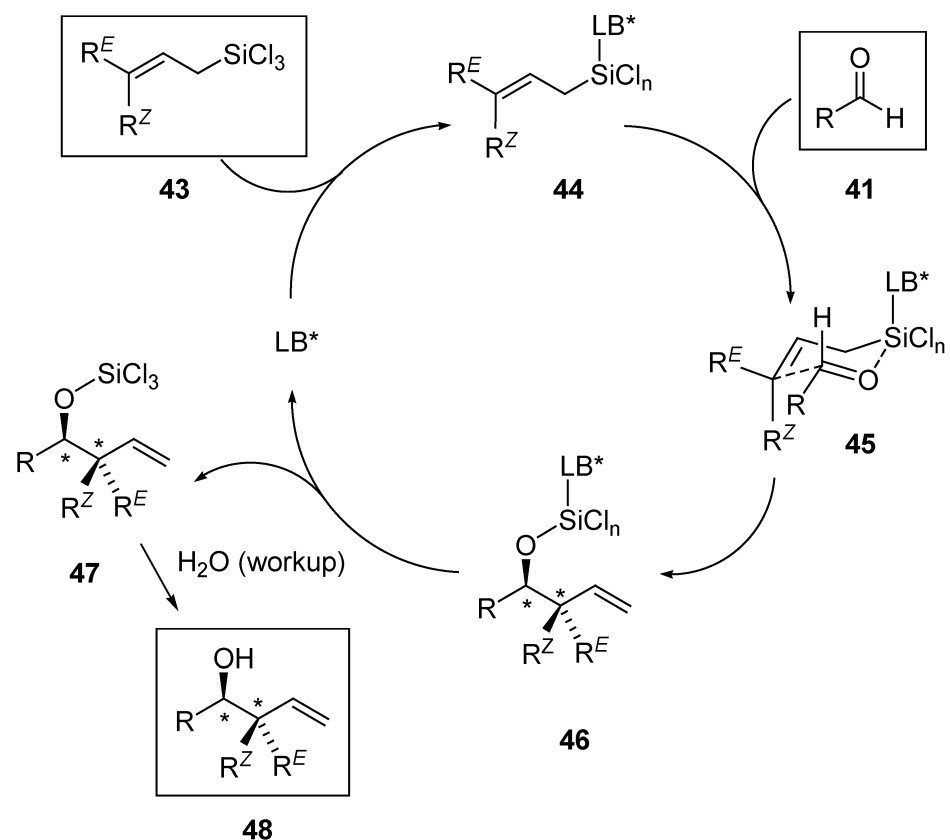

Scheme 10 Lewis base-catalyzed nucleophilic allylation of aldehydes.

Denmark has developed a series of chiral Lewis-basic phosphoramides, exhibiting good to high enantioselectivity in the allylation reaction [33,39-41]. However, these catalysts essentially represent chiral analogs of HMPA, which may affect their large-scale application in view of their potential toxicity.

Pyridine-type $N$-oxides (Scheme 11) represent another class of chiral Lewis-basic catalysts for the allylation reaction. Thus, Nakajima first demonstrated that the axially chiral biquinoline $N, N^{\prime}$-dioxide 49 can catalyze the allylation with high yields and enantioselectivity (71-92\% ee at $-78{ }^{\circ} \mathrm{C}$ ) [42]; in comparison, our terpene-derived $N, N^{\prime}$-dioxide $\mathbf{5 0}$ exhibited rather modest asymmetric induction [43]. These efforts were later followed by Hayashi, who reported good asymmetric induction attained with the bipyridine analog $\mathbf{5 1}$ and its congeners (with 56-98 \% ee) [44]. Catalyst $\mathbf{5 1}$ is remarkably reactive, so that its loading can be reduced to $0.1 \mathrm{~mol} \%$ level, and moderate activity is retained even at 0.01 mol \% loading [44], which renders $\mathbf{5 1}$ one of the most reactive organocatalyst reported to date. A chelation model, where both $\mathrm{N}$-oxide groups of the catalyst coordinate $\mathrm{Si}$ of the reagent, have been proposed to account for the reactivity [42-44]. 


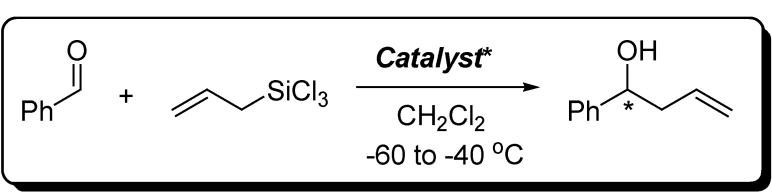

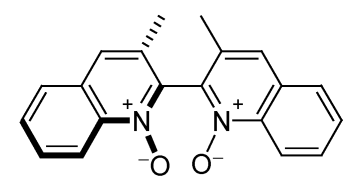

$49(88 \%$ ee, $R)$

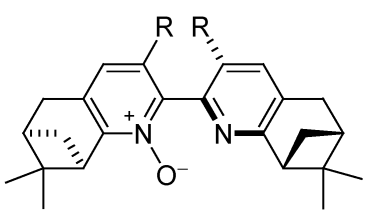

52, $\mathrm{R}=\mathrm{H} \quad(90 \%$ ee, $\mathrm{S})$ 53, $\mathrm{R}=\mathrm{Me}(98 \%$ ee, $\mathrm{S})$

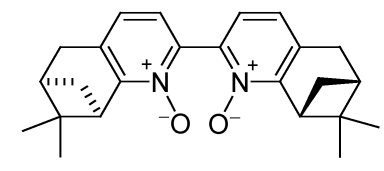

$50(41 \%$ ee, $R)$

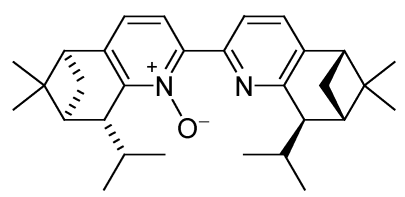

54 (97\% ee, S)

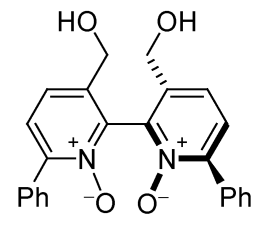

$51(84 \%$ ee, $S)$

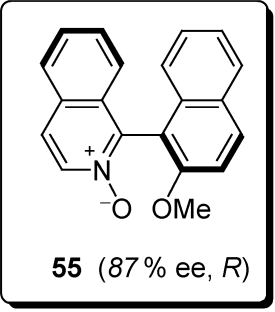<smiles>COc1cccc(OC(=O)C2CCCN2C(=O)c2ccccc2)c1-c1c(C)ccc[n+]1[O-]</smiles>

$56(68 \%$ ee, $S)$

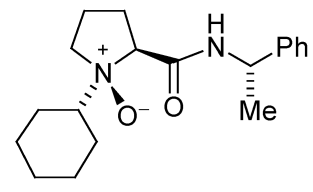

$57(87 \%$ ee, $R)$

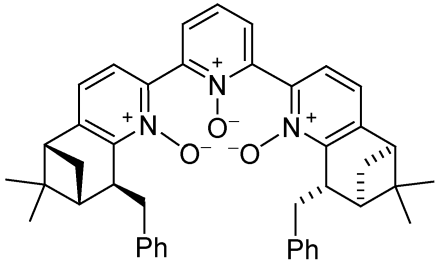

$58(86 \%$ ee, $R)$

Scheme $11 \mathrm{~N}$-Oxide organocatalysts for allylation of benzaldehyde with allyltrichlorosilane. The configuration of the resulting alcohol is shown in parentheses for each catalyst.

Prior to Hayashi's report [44], we [43] had introduced the terpene-derived bipyridine $\mathrm{N}$-monooxides 52-54 (PINDOX, $\mathrm{Me}_{2} \mathrm{PINDOX}$, and iso-PINDOX) as even more enantioselective catalysts than the bisoxide 49, although the reactions were slower, especially with the severely hindered iso-PINDOX (54). The most successful derivative of this series, $\mathrm{Me}_{2} \mathrm{PINDOX}(\mathbf{5 3})$, combines the effects of both central and axial chirality. However, the barrier to the rotation about the chiral axis is rather low, and as a result, $\mathbf{5 3}$ isomerizes within several days (in solution) to a 1:2 mixture of $\mathbf{5 3}$ and its atropoisomer, which attenuates the asymmetric induction [43b]. PINDOX (52) and iso-PINDOX (54) lack the restriction of the rotation, so that a suitable configuration is apparently established on coordination to the silicon atom of the allylating reagent [43]. In analogy to the $O, O$-chelation model proposed for dioxides 49-51, $O, N$-chelation of $\mathrm{Si}$ in AllylSiCl${ }_{3}$ by the $\mathrm{N}$-oxide group and the nitrogen of the second pyridine nucleus was considered for 52-54 [43]. Nevertheless, there was no direct evidence for the coordination to the nitrogen. Other $N$-oxides, namely, our QUINOX (55) [45] and derivatives 56-58 [46-48] have also been shown to catalyze the allylation reaction $[49,50]$. 
To address the issue of $\mathrm{N}, \mathrm{O}$-chelation, we have synthesized monodentate $\mathrm{N}$-oxides 59-63 lacking the second pyridine nucleus (Scheme 12). The dimethoxy derivative $\mathbf{5 9}$ turned out to catalyze the reaction effectively and exhibited $80 \%$ ee in the allylation of benzaldehyde [51,52]. METHOX (60) proved to be even more reactive and enantioselective (96\% ee at $1-5 \mathrm{~mol} \%$ loading, $-40{ }^{\circ} \mathrm{C}$ in $\mathrm{MeCN}$ ) [51,52], while its isomer $\mathbf{6 1}$ behaved in a similar way as 59. All these results suggest that coordination to nitrogen in 52-54 may either be absent or play a minor role. The comparison of 59, $\mathbf{6 0}$, and $\mathbf{6 1}$ shows that the steric bulk of the $\mathrm{MeO}$ groups in 2,6-positions (as in $\mathbf{5 9}$ and $\mathbf{6 0}$ ) cannot be solely responsible for the enantioselectivity, otherwise $\mathbf{6 1}$ (with the $\mathrm{MeO}$ groups in 3,4,5-positions) should exhibit much lower enantioselectivity than 59/60, while $\mathbf{6 0}$ would not be expected to be superior to $\mathbf{5 9}$ (owing to the same substitution pattern in the vicinity of the reaction center). Interestingly, the phenyl derivative $\mathbf{6 2}$, lacking the $\mathrm{MeO}$ groups, also turned out to catalyze the allylation, though with lower enantioselectivity (41\% ee) [51]. By contrast, the electron-poor di-trifluoromethyl derivative $\mathbf{6 3}$ proved practically inert, demonstrating that an electron-rich aromatic moiety in the catalyst (as in 60) is beneficial to the reaction, whereas an electron-poor unit renders the molecule catalytically inactive.

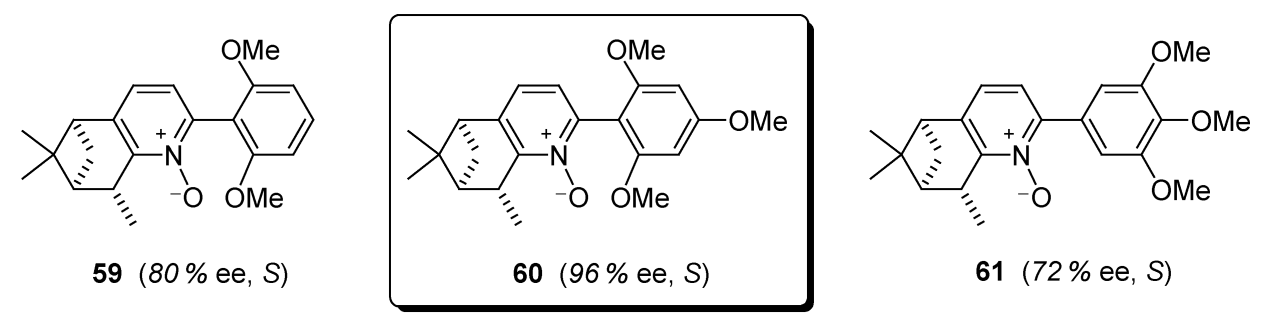

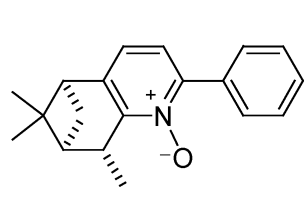

$62(41 \%$ ee, S)

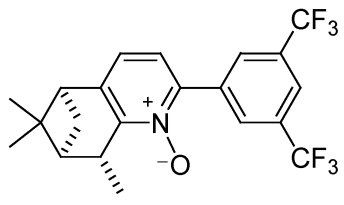

63 (practically no reaction)

Scheme 12 Electronic effects of the $N$-oxide monodentate catalysts on the enantioselectivity of allylation of benzaldehyde. The configuration of the resulting alcohol is shown in parentheses for each catalyst.

The latter behavior suggests that arene-arene interactions between the catalyst and the substrate play an important role. For the $N, N$-dioxide catalyst 51, Hayashi reported a variation of enantioselectivity as a function of the electronic properties of substituted benzaldehydes 64 in the range of 56-94\% ee, with the electron-rich $p$-methoxy benzaldehyde (64c) giving the highest selectivity (Scheme 13) [44]. By contrast, little variation was observed for our electron-rich METHOX 60 (Scheme 13) [52]. On the other hand, our QUINOX (55) exhibited a strong dependence of selectivity on the Ar group (within the range of 16-96 \% ee!) but in the opposite direction than Hayashi's 51, giving the best results with the electron-poor $\mathbf{6 4 b}$ [45].

The intriguing behavior of QUINOX (55) was further elucidated with the aid of kinetic and computational methods and isotopic labeling. This approach has allowed the formulation of an associative mechanism with the difference in the transition-state (TS) barriers $\Delta \Delta G^{\neq}=2.0 \mathrm{kcal} \mathrm{mol}^{-1}$ in favor of the $(R)$ reaction channel [45b,53]. This figure predicts the formation of $(R)-\mathbf{6 5 a}$ in $98 \%$ ee, which is in a good agreement with the experimental value of $87 \%$ ee. The dissociative route was found to be higher in energy, and would favor the formation of the opposite, i.e., $(S)$-enantiomer. In the case of $p$-methoxybenzaldehyde $(\mathbf{6 4 c})$, the associative mechanism is also favored but with only $0.8 \mathrm{kcal} \mathrm{mol}^{-1}$ difference in the TS barriers for the formation of the individual enantiomers. This energy gap predicts the formation of $(R)-65 \mathrm{c}$ in $62 \%$ ee (45\% ee observed experimentally at $273 \mathrm{~K}$ [45]). The calculations further 


\begin{tabular}{|c|c|c|c|}
\hline \multirow{2}{*}{$\begin{array}{l}\mathrm{Ar}^{\mathrm{O}}+ \\
64 \mathrm{a}-\mathrm{c}\end{array}$} & \multicolumn{2}{|c|}{ Catalyst ${ }^{*}$} & $\mathrm{OH}$ \\
\hline & -40 & & \\
\hline 64 & 51 & 55 & 60 \\
\hline 64 & $\% /$ ee & $\% /$ ee & $\% /$ ee \\
\hline a, $\mathrm{Ar}=\mathrm{Ph}$ & $95 / 84$ & $60 / 87$ & $95 / 96$ \\
\hline b, $\mathrm{Ar}=4-\mathrm{CF}_{3}-\mathrm{Ph}$ & $83 / 56$ & $85 / 96$ & $86 / 93$ \\
\hline c, $\mathrm{Ar}=4-\mathrm{MeO}-\mathrm{Ph}$ & $96 / 94$ & $70 / 12$ & $95 / 96$ \\
\hline
\end{tabular}

Scheme 13 Electronic effect in the aldehyde on the allylation catalyzed by selected $N$-oxides $(\mathbf{5 1}, \mathbf{5 5}$, and $\mathbf{6 0})$.

showed that the methoxynaphthalene unit of QUINOX (55) and benzaldehyde ( $\mathrm{PhCHO})$ in the TS are arranged in a parallel orientation, allowing $\pi-\pi$ interactions [45b].

\section{CONCLUSIONS}

Two approaches to allylation, with the opposite polarity of the allylic unit, were discussed. Our contribution to the stereo- and enantiocontrol in the transition-metal-catalyzed allylic substitution has been summarized ( $\mathrm{Pd}, \mathrm{Mo}$, and $\mathrm{Ni}$ ). Ir-catalyzed substitution (as an example, where the allylic unit acts as an electrophile) has now been employed in our new approach to $C$-nucleoside analogs, where the $\mathrm{C}-\mathrm{O}$ (rather than $\mathrm{C}-\mathrm{C}$ ) was constructed stereospecifically. Variation of the absolute configuration in the starting segments allowed the synthesis of all combination of $D / L-\alpha / \beta$-ribosides. The opposite polarity in the allylation, where allylsilanes act as nucleophiles, has been discussed in the second part and new chiral, Lewis-basic catalysts revealed. The intriguing mode of action of QUINOX (55) has been studied and a likely mechanism formulated, which involves the $\pi-\pi$ interaction between the substrate aldehyde and the catalyst. Good correlation between the calculated energies for the TSs and the experimentally observed enantioselectivities have been obtained.

\section{ACKNOWLEDGMENTS}

We thank the many coworkers who participated in various parts of these projects and whose names appear in the reference section, in particular, Profs. Ivo Starý, Dalimil Dvořák, and Marco Bella, and Drs. Jan Štambaský, Mark Bell, Fabio Castelluzzo, Filip Teplý, Lenka Duchková, Monica Orsini, Daniele Pernazza, Lada Bendová, Mary-M. Westwater, and Pedro Ramírez-López. We also thank Prof. Guy C. Lloyd-Jones and Dr. Lubomír Rulíšek for a long-term collaboration and many fruitful discussions. We acknowledge the support from the University of Glasgow, EPSRC, the Socrates-Erasmus Exchange Program, the Spanish Ministry of Education, GlaxoSmithKline, Pfizer, AstraZeneca, Organon, Eastman, and Takasago. Finally, we would like to thank Dr. Alfred Bader for continued support and personal donations.

\section{REFERENCES AND NOTES}

1. (a) R. M. Magid. Tetrahedron 36, 1901 (1980); (b) L. A. Paquette, C. J. M. Stirling. Tetrahedron 48, 7383 (1992). 
2. For reviews, see: (a) B. M. Trost. Tetrahedron 33, 371 (1977); (b) B. M. Trost. Acc. Chem. Res. 13, 385 (1980); (c) J. Tsuji. Tetrahedron 42, 4361 (1986); (d) C. G. Frost, J. Howarth, J. M. J. Williams. Tetrahedron: Asymmetry 3, 1089 (1992); (e) J.-E. Bäckvall. Acta Chem. Scand. 50, 661 (1996); (f) B. M. Trost. Acc. Chem. Res. 29, 355 (1996); (g) E. Negishi (Ed.). Handbook of Palladium Chemistry for Organic Synthesis, Vol. 2, p. 1663, John Wiley, New York (2002).

3. (a) I. Starý, P. Kočovský. J. Am. Chem. Soc. 111, 4981 (1989); (b) I. Starý, J. Zajíček, P. Kočovský. Tetrahedron 48, 7229 (1992); (c) C. N. Farthing, P. Kočovský. J. Am. Chem. Soc. 120, 6661 (1998); for a personal overview, see: (d) P. Kočovský. J. Organomet. Chem. 687, 256 (2003).

4. (a) H. Kurosawa, S. Ogoshi, Y. Kawasaki, S. Murai, M. Miyoshi, I. Ikeda. J. Am. Chem. Soc. 112, 2813 (1990); (b) H. Kurosawa, H. Kajimaru, S. Ogoshi, H. Yoneda, K. Miki, N. Kasai, S. Murai, I. Ikeda. J. Am. Chem. Soc. 114, 8417 (1992).

5. (a) M. E. Krafft, A. M. Wilson, Z. Fu, M. J. Procter, O. A. Dasse. J. Org. Chem. 63, 1748 (1998); (b) G. R. Cook, H. Yu, S. Sankaranarayanan, P. S. Shanker. J. Am. Chem. Soc. 125, 5115 (2003); (c) K. Nehri, J. Franzén, J.-E. Bäckvall. Chem.-Eur. J. 11, 6937 (2005); the steering of Pd by a neighboring group has then been utilized for a diastereoselective control in substrates with a nonchiral allylic moiety: (d) A. G. Jamieson, A. Sutherland. Org. Lett. 9, 1609 (2007) and refs. cited therein.

6. Mo: (a) B. M. Trost, M. Lautens. J. Am. Chem. Soc. 104, 5543 (1982); (b) B. M. Trost, C. A. Merlic. J. Am. Chem. Soc. 112, 9590 (1990) and refs. cited therein; (c) M. P. T. Sjögren, H. Frisell, B. Åkermark, P. O. Norrby, L. Eriksson, A. Vitagliano. Organometallics 16, 942 (1997).

7. W: (a) B. M. Trost, M.-H. Hung. J. Am. Chem. Soc. 105, 7757 (1983); (b) J. Lehmann, G. C. Lloyd-Jones. Tetrahedron 51, 8863 (1995); (c) H. Frisell, B. Åkermark. Organometallics 14, 561 (1995).

8. D. Dvořák, I. Starý, P. Kočovský. J. Am. Chem. Soc. 117, 6130 (1995).

9. For stoichiometric studies, see: (a) J. W. Faller, D. Linebarrier. Organometallics 7, 1670 (1988); (b) Y. D. Ward, L. A. Villanueva, G. D. Allred, L. S. Liebeskind. J. Am. Chem. Soc. 118, 897 (1996).

10. (a) G. C. Lloyd-Jones, S. W. Krska, D. L. Hughes, L. Gouriou, V. D. Bonnet, K. Jack, Y. Sun, R. A. Reamer. J. Am. Chem. Soc. 126, 702 (2004); (b) J. A. R. Luft, Z.-X. Yu, D. L. Hughes, C. G. Lloyd-Jones, S. W. Krska, K. N. Houk. Tetrahedron: Asymmetry 17, 716 (2006); see also: (c) M. E. Krafft, M. J. Procter, K. A. Abboud. Organometallics 18, 1122 (1999).

11. P. A. Evans, J. D. Nelson. J. Am. Chem. Soc. 120, 5581 (1998).

12. (a) P. A. Evans, D. K. Leahy, W. J. Andrews, D. Uraguchi. Angew. Chem., Int. Ed. 43, 4788 (2004); (b) P. A. Evans, D. K. Leahy, L. M. Slieker. Tetrahedron: Asymmetry 14, 3613 (2003).

13. C. Shu, J. F. Hartwig. Angew. Chem., Int. Ed. 43, 4794 (2004).

14. (a) V. Bohrsch S. Blechert. Chem. Commun. 1968 (2006); for a feature article, see: (b) G. Helmchen, A. Dahnz, P. Dübon M. Schelwies, R. Weihofen. Chem. Commun. 675 (2007).

15. R. Prétôt, A. Pfaltz. Angew. Chem., Int. Ed. 37, 323 (1998).

16. (a) J. C. Fiaud, J. L. Malleron. Tetrahedron Lett. 22, 1399 (1981); (b) B. M. Trost, N. R. Schmuff. Tetrahedron Lett. 22, 2999 (1981); (c) B. M. Trost, R. C. Bunt. J. Am. Chem. Soc. 118, 235 (1996); (d) T. Hayashi, M. Kawatsura, Y. Uozumi. J. Am. Chem. Soc. 120, 1681 (1998); (e) G. C. Lloyd-Jones, S. C. Stephen. Chem._Eur. J. 4, 2539 (1998); (f) G. C. Lloyd-Jones, S. C. Stephen. Chem. Commun. 2321 (1998); (g) C. P. Butts, J. Crosby, G. C. Lloyd-Jones, S. C. Stephen. Chem. Commun. 1707 (1997); (h) A. J. Blacker, M. L. Clarke, M. S. Loft, J. M. J. Williams. Org. Lett. 1, 1969 (1999); (i) U. Burckhardt, M. Baumann, A. Togni. Tetrahedron: Asymmetry 8, 155 (1997). 
17. (a) Š. Vyskočil, M. Smrčina, V. Hanuš, M. Polášek, P. Kočovský. J. Org. Chem. 63, 7738 (1998); (b) P. Kočovský, Š. Vyskočil, I. Císařová, J. Sejbal, I. Tišlerová, M. Smrčina, G. C. Lloyd-Jones, S. C. Stephen, C. P. Butts, M. Murray, V. Langer. J. Am. Chem. Soc. 121, 7714 (1999); (c) G. C. Lloyd-Jones, S. C. Stephen, M. Murray, C. P. Butts, Š. Vyskočil, P. Kočovský. Chem.-Eur. J. 6, 4348 (2000); (d) I. J. S. Fairlamb, G. C. Lloyd-Jones, Š. Vyskočil, P. Kočovský. Chem.—Eur. J. 8, 4443 (2002); (e) L. Gouriou, G. C. Lloyd-Jones, Š. Vyskočil, P. Kočovský. J. Organomet. Chem. 687, 525 (2003); for overviews, see ref. [3d] and: (f) P. Kočovský, A. Malkov, Š. Vyskočil, G. C. Lloyd-Jones. Pure Appl. Chem. 71, 1425 (1999).

18. For overviews, see: (a) B. M. Trost, D. L. Van Vranken. Chem. Rev. 96, 395 (1996); (b) G. Helmchen, A. Pfaltz. Acc. Chem. Res. 33, 336 (2000); (c) G. Helmchen, S. Kudis, P. Sennhenn, H. Steinhagen. Pure Appl. Chem. 69, 513 (1997).

19. (a) B. M. Trost, I. Hachiya. J. Am. Chem. Soc. 120, 1104 (1998); (b) F. Glorius, A. Pfaltz. Org. Lett. 1, 141 (1999); (c) F. Glorius, M. Neuburger, A. Pfaltz. Helv. Chim. Acta 84, 3178 (2001); (d) O. Belda, N.-F. Kaiser, U. Bremberg, M. Larhed, A. Hallberg, C. Moberg. J. Org. Chem. 65, 5868 (2000); (e) N.-F. Kaiser, U. Bremberg, M. Larhed, C. Moberg, A. Hallberg. Angew. Chem., Int. Ed. 39, 3596 (2000).

20. (a) A. V. Malkov, P. Spoor, V. Vinader, P. Kočovský. Tetrahedron Lett. 42, 509 (2001); (b) A. V. Malkov, I. Starý, L. Gouriou, G. C. Lloyd-Jones, V. Langer, P. Spoor, V. Vinader, P. Kočovský. Chem.-Eur. J. 12, 6910 (2006); see also ref. [17f].

21. (a) E. T. Kool, J. C. Morales, K. M. Guckian. Angew. Chem., Int. Ed. 39, 990 (2000); (b) A. T. Krueger, H. Lu, A. H. F. Lee, E. T. Kool. Acc. Chem. Res. 49, 141 (2007); for the most recent contribution, see: (c) A. T. Krueger, E. T. Kool. J. Am. Chem. Soc. 130, 3989 (2008).

22. (a) Q. Wu, C. Simons. Synthesis 1533 (2004); (b) K. W. Wellington, S. A. Benner. Nucl. Ac. 25, 1309 (2006); (c) M. Urban, R. Pohl, B. Klepetářová, M. Hocek. J. Org. Chem. 71, 7322 (2006).

23. D. Tomita, R. Wada, M. Kanai, M. Shibasaki. J. Am. Chem. Soc. 127, 4138 (2005).

24. For the method, see: E. J. Stoner, M. J. Peterson, M. S. Allen, J. A. DeMattei, A. R. Haight, M. R. Leanna, S. R. Patel, D. J. Plata, R. H. Premchandran, M. Rasmussen. J. Org. Chem. 68, 8847 (2003); other methods, such as derivatization of 29 directly with (BOC) $2 \mathrm{O}$ or $\mathrm{BOCCl}$ in the presence of DMAP, or using the sodium alkoxide (generated from 29 and $\mathrm{NaH}$ ) proved less satisfactory, as they led to the formation of larger proportions of the isomeric cinnamyl products.

25. (a) B. Feringa. Acc. Chem. Res. 33, 346 (2000); (b) K. Tissot-Vroset, D. Polet, A. Alexakis. Angew. Chem., Int. Ed. 43, 2426 (2004).

26. The related approach, using Rh catalysts [12] was less stereoselective.

27. For the method, see: A. K. Chatterjee, T.-L. Choi, D. P. Sanders, R. H. Grubbs. J. Am. Chem. Soc. 125, 11360 (2003).

28. Ru/Ce: (a) B. Plietker, M. Niggemann. J. Org. Chem. 70, 2402 (2005); Ru/Yb: (b) S. Beligny, S. Eibauer, S. Maechling, S. Blechert. Angew. Chem., Int. Ed. 45, 1900 (2006); Ru: (c) T. Hudlický, U. Rinner, D. Gonzalez, H. Akgun, S. Schilling, P. Siengalewicz, T. A. Martinot, G. R. Pettit. J. Org. Chem. 67, 8726 (2002).

29. For the recently developed enantioselective Nozaki-Hiyama-Kishi allylation, see: G. C. Hargaden, H. A. McManus, P. G. Cozzi, P. J. Guiry. Org. Biomol. Chem. 5, 763 (2007).

30. E. N. Jacobsen, A. Pfaltz, H. Yamamoto. Comprehensive Asymmetric Catalysis, Vols. I-III, Springer, Heidelberg (1999).

31. (a) S. Kobayashi, K. Nishio. Tetrahedron Lett. 34, 3453 (1993); (b) S. Kobayashi, K. Nishio. J. Org. Chem. 59, 6620 (1994); (c) S. Kobayashi, K. Nishio. Synthesis 457 (1994).

32. J. D. Short, S. Attenoux, D. J. Berrisford. Tetrahedron Lett. 38, 2351 (1997).

33. S. E. Denmark, D. M. Coe, N. E. Pratt, B. D. Griedel. J. Org. Chem. 59, 6161 (1994).

34. Z. Wang, G. Xu, D. Wang, M. E. Pierce, P. N. Confalone. Tetrahedron Lett. 41, 4523 (2000). 
35. Allyl trichlorosilane is conveniently prepared from allyl chloride, $\mathrm{Cl}_{3} \mathrm{SiH}, \mathrm{CuCl}$, and $(i-\mathrm{Pr})_{2} \mathrm{EtN}$ (or $\mathrm{Et}_{3} \mathrm{~N}$ ) in ether at $20{ }^{\circ} \mathrm{C}$ : (a) S. Kobayashi, K. Nishio. Chem. Lett. 1773 (1994); (b) M. Nakajima, M. Saito, S. Hashimoto. Chem. Pharm. Bull. 48, 306 (2000); for an overview of the various other methods, see: (c) P. Kočovský. In Encyclopedia of Reagents for Organic Synthesis "eEROS", L. A. Paquette (Ed.), John Wiley, New York (2004).

36. (a) P. Kočovský, A. V. Malkov. "Chiral Lewis bases as catalysts", in Enantioselective Organocatalysis: Reactions and Experimental Procedures, P. Dalko (Ed.), p. 255. Wiley-VCH, Weinheim (2007); (b) S. E. Denmark, J. Fu. Chem. Rev. 103, 2763 (2003); (c) S. E. Denmark, G. L. Beutner. Angew. Chem., Int. Ed. 47, 1560 (2008).

37. trans-Crotyl trichlorosilane can be synthesized from trans-crotyl chloride, $\mathrm{Cl}_{3} \mathrm{SiH}, \mathrm{CuCl}$, and $(i \text {-Pr })_{2}$ EtN in ether at $20^{\circ} \mathrm{C}$; see ref. [35] and the following: (a) S. Aoki, K. Mikami, M. Terada, T. Nakai. Tetrahedron 49, 1783 (1993); (b) F. D’Aniello, M. Falorni, A. Mann, M. Taddei. Tetrahedron: Asymmetry 7, 1217 (1996); (c) K. Iseki, Y. Kuroki, M. Takahashi, S. Kishimoto, Y. Kobayashi. Tetrahedron 53, 3513 (1997); (d) A. Shibato, Y. Itagaki, E. Tayama, Y. Hokke, N. Asao, K. Maruoka. Tetrahedron 56, 5373 (2000); for an alternative, utilizing trans-crotyl chloride, $\mathrm{SiCl}_{4}$, and $\mathrm{Cp}_{2} \mathrm{Ni}$ in HMPA at $90{ }^{\circ} \mathrm{C}$, see: (e) R. Calas, J. Dunogues, G. Deleris, N. Duffaut. J. Organomet. Chem. 225, 117 (1982); (f) M. Lefort, C. Simmonet, M. Birot, G. Deleris, J. Dunogues, R. Calas. Tetrahedron Lett. 21, 1857 (1980); yet another alternative, using transcrotyl chloride with $\mathrm{Cl}_{3} \mathrm{SiH}$ and $\mathrm{Bu}_{4} \mathrm{PCl}$ at $150{ }^{\circ} \mathrm{C}$ has also been reported: (g) Y.-S. Cho, S.-H. Kang, J. S. Han, B. R. Yoo, N. Jung. J. Am. Chem. Soc. 123, 5584 (2001); for an overview, see: (h) P. Kočovský. Encyclopedia of Reagents for Organic Synthesis “eEROS”, L. A. Paquette (Ed.), John Wiley, New York (2004).

38. cis-Crotyl trichlorosilane can be prepared via the 1,4-addition of $\mathrm{Cl}_{3} \mathrm{SiH}$ to butadiene, catalyzed by $(\mathrm{PhCN})_{2} \mathrm{PdCl}_{2}$ or $\left(\mathrm{Ph}_{4} \mathrm{P}\right)_{4} \mathrm{Pd}$ (at 20 or $-78{ }^{\circ} \mathrm{C}$ ). For the former catalysts, see: (a) M. Kira, K. Sato, H. Sakurai. J. Am. Chem. Soc. 110, 4599 (1988); (b) M. Kira, L. C. Zhang, C. Kabuto, H. Sakurai. Organometallics 17, 887 (1998); for an overview, see: (c) H. Sakurai. Synlett 1 (1998); for the use of the latter catalyst, see ref. [36c] and the following: (d) J. Tsuji, M. Hara, K. Ohno. Tetrahedron 30, 2143 (1974); (e) M. Wadamoto, N. Ozasa, A. Yanagisawa, H. Yamamoto. J. Org. Chem. 63, 5593 (2003); (f) K. Iseki, Y. Kuroki, M. Takahashi, Y. Kobayashi. Tetrahedron Lett. 37, 5149 (1996); this hydrosilylation can also be catalyzed by Ni: (g) M. Čapka, J. Hetflejš. Collect. Czech. Chem. Commun. 40, 2073 (1975); (h) M. Čapka, J. Hetflejš. Collect. Czech. Chem. Commun. 40, 3020 (1975); an uncatalyzed reaction occurs at 500-600 ${ }^{\circ}$ C: (i) J. Heinicke, I. Kirst, B. Gehrhus, A. Tzschach. Z. Chem. 28, 261 (1988); for an overview, see ref. [37h].

39. (a) S. E. Denmark, D. M. Coe, N. E. Pratt, B. D. Griedel. J. Org. Chem. 59, 6161 (1994); (b) S. E. Denmark, J. Fu. J. Am. Chem. Soc. 122, 12021 (2000); (c) S. E. Denmark, J. Fu. J. Am. Chem. Soc. 123, 9488 (2001); (d) S. E. Denmark, J. Fu. Org. Lett. 4, 1951 (2002); (e) S. E. Denmark, J. Fu. J. Am. Chem. Soc. 125, 2208 (2003); (f) S. E. Denmark, J. Fu, D. M. Coe, X. Su, N. E. Pratt, B. D. Griedel. J. Org. Chem. 71, 1513 (2006); (g) S. E. Denmark, J. Fu. J. Am. Chem. Soc. 122, 12021 (2000); (h) S. E. Denmark, J. Fu, D. M. Coe, X. Su, N. E. Pratt, B. D. Griedel. J. Org. Chem. 71, 1513 (2006); for mechanistic studies on the related aldol reaction, see: (i) S. E. Denmark, T. Bui. Proc. Natl. Acad. Sci. USA 101, 5439 (2004); (j) S. E. Denmark, T. Bui. J. Org. Chem. 70, 10393 (2005); (k) S. E. Denmark, S. M. Pham, R. A. Stavenger, X. Su, K.-T. Wong, Y. Nishigaichi. J. Org. Chem. 71, 3904 (2006); for mechanistic studies on Lewis base-catalyzed opening of epoxides with chlorosilanes, see: (l) S. E. Denmark, P. A. Barsanti, G. L. Beutner, T. W. Wilson. Adv. Synth. Catal. 349, 567 (2007).

40. J. Hellwig, T. Belser, J. F. K. Müller. Tetrahedron Lett. 42, 5417 (2001).

41. Chiral phosphoramidates attached to polystyrene have also been reported to exhibit asymmetric induction in the allylation of $\mathrm{PhCHO}$ with $\mathrm{AllylSiCl}_{3}$ ( $\leq 63 \%$ ee): T. Oyama, H. Yoshioka, M. Tomoi. J. Chem. Soc., Chem. Commun. 1857 (2005). 
42. (a) M. Nakajima, M. Saito, M. Shiro, S. Hashimoto. J. Am. Chem. Soc. 120, 6419 (1998); (b) M. Nakajima, M. Saito, S. Hashimoto. Chem. Pharm. Bull. 48, 306 (2000).

43. (a) A. V. Malkov, M. Orsini, D. Pernazza, K. W. Muir, V. Langer, P. Meghani, P. Kočovský. Org. Lett. 4, 1047 (2002); (b) A. V. Malkov, M. Bell, M. Orsini, D. Pernazza, A. Massa, P. Herrmann, P. Meghani, P. Kočovský. J. Org. Chem. 68, 9659 (2003); for reviews, see: (c) A. V. Malkov, P. Kočovský. Curr. Org. Chem. 7, 1737 (2003); (d) P. Kočovský, A. V. Malkov. Izv. Akad. Nauk, Ser. Khim. 1733 (2004); (e) P. Kočovský, A. V. Malkov. Russ. Chem. Bull., Int. Ed. 59, 1806 (2004); (f) A. V. Malkov, P. Kočovský. Eur. J. Org. Chem. 29 (2007).

44. (a) T. Shimada, A. Kina, S. Ikeda, T. Hayashi. Org. Lett. 4, 2799 (2002); (b) T. Shimada, A. Kina, T. Hayashi. J. Org. Chem. 68, 6329 (2003); (c) A. Kina, T. Shimada, T. Hayashi. Adv. Synth. Catal. 346, 1169 (2004).

45. (a) A. V. Malkov, L. Dufková, L. Farrugia, P. Kočovský. Angew. Chem., Int. Ed. 42, 3674 (2003); (b) A. V. Malkov, M. Bell, P. Ramírez-López, L. Biedermannová, L. Rulíšek, L. Dufková, M. Kotora, F. Zhu, P. Kočovský. J. Am. Chem. Soc. 130, 5341 (2008).

46. L. Pignataro, M. Benaglia, R. Annunziata, M. Cinquini, F. Cozzi. J. Org. Chem. 71, 1458 (2006).

47. J. F. Traverse, Y. Zhao, A. H. Hoveyda, M. L. Snapper. Org. Lett. 7, 3151 (2005).

48. W.-L. Wong, C.-S. Lee, H. K. Leung, H.-L. Kwong. Org. Biomol. Chem. 1967 (2004).

49. Chiral sulfoxides also promote an enantioselective reaction but with moderate enantioselectivity; the process is not catalytic: A. Massa, A. V. Malkov, P. Kočovský, A. Scettri. Tetrahedron Lett. 44, 7179 (2003).

50. Analogous catalytic allyboration requires a metal catalyst (e.g., $\mathrm{CuF}_{2}$ with DuPHOS): R. Wada, K. Oisaki, M. Kanai, M. Shibasaki. J. Am. Chem. Soc. 126, 8910 (2004).

51. A. V. Malkov, M. Bell, M. Vassieu, V. Bugatti, P. Kočovský. J. Mol. Catal. A 196, 179 (2003).

52. A. V. Malkov, M. Bell, F. Castelluzzo, P. Kočovský. Org. Lett. 7, 3219 (2005).

53. The calculated values for $\Delta G^{\neq}$were obtained at the RI-PBE(+D)/TZVP//RI-PBE(+D)/6-31G(d) level. 